\title{
Explorations into the epigenetic space
}

\author{
Diddahally R Govindaraju
}

\section{Book details}

Epigenetics: Linking Genotype and Phenotype in Development and Evolution, Hallgrimsson, B and Hall BK (Editors). University of California Press, Berkeley, Los Angeles, London. Viii + 459 pages, ISBN: 978-0-520-26709-I, Price: $\$ 85.45$.

Much of the theoretical and empirical basis of the modern evolutionary synthesis, and progress in applied genetics (e.g., plant and animal breeding), has been built on the premise that gene frequency changes in populations, in time (across generations) and space, occur due to the action of evolutionary forces. Empirical estimates of gene frequencies serve as indices to quantify micro-evolutionary changes. During the first two decades of this phase in the $20^{\text {th }}$ century, however, only a few scientists such as Archibald Garrod, Sewall Wright and J. B. S. Haldane sought to understand the links between gene and genotype on the one hand, and phenotype on the other, in relation to environment. They also speculated that paths between genotype and phenotype are mediated by enzymes, and their interactions with each other, as well as with the environment, could manifest as normal, abnormal or disease phenotypes. Natural selection acts on the resultant individual phenotypes. Their work contributed to much of the subsequent developments in molecular, medical an evolutionary genetics. Sewall Wright has summarized his earlier work related to this area of genetics starting from 1916, in a paper entitled "Physiological and evolutionary theories of dominance" (Wright 1934). A part of the second section of this paper deals with "the factors of development", in which he stated that, "It (the physiological explanation of dominance) involves the whole question of the mechanism of control of the developmental process. However, the present states of knowledge of embryology and physiology impose certain limitations on speculation. We are sure, for example, that development is an epigenetic processes (emphasis mine). The genes cannot stand in the simple one to one relation to morphological

Correspondence: drgrajugis@gmail.com

The Institute for Aging Research, Albert Einstein College of Medicine, 1300 Morris Park Ave., Bronx, NY 10461, USA characters of a pre-formationist theory. Genetic data are of course in harmony. Each character is affected by many genes and each gene affects many characters". What a prescient statement! A graphical representation of these ideas is provided in figure 1 of Wright's above paper with the legend: "...relation of factors (genes) to any developmental process of a vertebrate, occurring at a particular time and place". In the same paper, he has also discussed the relationships among genes, enzymes and their phenotypic effects in terms of rate limiting properties of enzymes or flux - a topic later elaborated by Kacser and Burns (1981).

But the daunting question, how a tiny fertilized egg a cell - differentiates and grows into a complex organism capable of carrying out complex functions, associated with survival and reproduction, from birth to death remained elusive. While Wright and his contemporaries were developing mathematical theories to explain evolutionary processes and continued to do so, embryologist Conrad Hal Waddington started to explore these questions more formally starting with his famous paper "The Epigenetics". In this paper, he described the general features of an "epigenotype" as one that "consists of concatenations of processes linked together in a network, so that a disturbance at an early stage may gradually cause more and more far reaching abnormalities in many different organs and tissues" (Waddington 1942). He later defined epigenetics as "causal interactions of genes and their products which bring the phenotype into being' (Waddington 1975). This view closely resembles that of Wright's ideas on physiological flows and causality, who also invented path analysis, specifically to analyze physical and physiological chains of causes, direction of their flows and their ultimate effects (Wright 1921). He subsequently extended this technique to explore causality in biological systems. Various authors have discussed Wright's influence on Waddington particularly with reference to his epigenetic landscape metaphor (Fusco et al. 2014). According to the Wright-Waddington model, the space between genotype and phenotype (G-P space; Lewontin 1974), where epigenetic processes take place, may be viewed as the embedded system which orchestrates much of the antecedent and attendant properties of the G-P space. 
Despite initial hesitation (largely due to Lamark's anthropocentric views of evolution), interest on the role of epigenetics and developmental biology in evolution and health has surged in recent years, under the acronym "evo-devo". Twenty three articles in the present book, edited by Halgrimsson and Hall, provide a glimpse into these exciting developments in this relatively nascent branch of biology. These chapters are divided into four sections: a) historical and philosophical foundations, b) approaches to epigenetics, c) epigenetics of vertebrate organ development, and d) epigenetics in evolution and disease. The editors have provided an excellent introductory chapter on epigenetics, and conclude with a chapter on epigenetics from a logical multilevel perspective. These sections indeed conform broadly to Waddington's above definition. Authors of chapters 4-7 have synthesized diverse epigenetic processes. In particular, they view methylation and imprinting as primary phenotypes of genes (epi-genomic) and components of the larger phenome (i. e., every thing outside or on top of genome or extragenomic or phenotypic) is appealing, because specific epigenetic changes could be quantified in relation to age, stage and sex as well as targets of natural selection during developmental process. Direct, indirect, mediated, reverse, truncated and reticulated gene action could occur in the system of epigenetic space as conceived by both Wright and Waddington. Some of the causal and contextual effects of genes may be expressed in the ultimate phenotype in relation to environment. Chapters 9- 15 deal with the ways epigenetic factors operate in relation to pattern formation among specific anatomical structures during development and influence their mutual relationships. Chapters 16-22 present more applied aspects of epigenetics and discuss the relationship between epigenetic factors and phenotypic diversity. These suggest how genetic, physiological, anatomical and morphological structures interact as a system to produce highly conserved shapes, and also impose constraints on the maintenance and evolution of phenotypic plasticity. The latter could operate at all levels of biological organization - individual, family and population - eventually leading to local adaptations and radiation. The subject of chapters 21 and 22 come extremely close to Waddington's original definition of epigenetics (see above). Any perturbations in the genetic and epigenetic system as well as in utero changes could affect allometric relationships among physiological and morphological traits during development and some of which may be expressed, later in life as advanced by developmental origins of health and disease (DoHAD) concept (Chapter 22). Insights provided in these chapters hold promise for developing appropriate medical interventions, particularly against developmental and metabolic disorders.

This book represents an excellent, logically organized and well-produced collection of articles. I have a few concerns, however. Parts of chapters 2 and 8 are both verbose and vague. Chapter 2 opens up nicely and identifies the dichotomy between molecular biologists and evolutionary biologists. Later it meanders. However, partial answers to some of the concerns raised in chapter 2 are provided in chapters 21 and 22 . With the emerging technologies, one could measure many epigenetic changes (Chapter 5) in humans at all hierarchical levels of biological organization, and monitor their progress during development and growth more accurately than we could ever attempt to do previously. Hence, epigenetics no longer remains in a theoretical or speculative domain. The first paragraph in chapter 8 reads: "Biology has long suffered from comparison with physics - biology is largely concerned with the description of historically determined phenomena, rather than with eternal laws. Recently, however, the status of biology has increased substantially, largely because of its success in studying genes and their expression and because of the widely appreciated importance of life sciences for the welfare of humanity and to safeguard our living space on Earth", and this line of reasoning continues throughout. Although developmental inertia is an interesting concept, life processes hardly ever come to a screeching halt (like seed dormancy). Mechanistic views may occasionally serve as useful comparisons for lay audience, but their utility even in the medical sciences (which is built upon the notion that human body is like a machine and hence could be fixed) is only marginally useful. Also, the book draws a great deal of examples from animal research. Excellent work on epigenetic variation, particularly in flax and in corn is ignored. I also believe that a chapter on systems approaches with examples (say, causality, Bayesian networks, path analysis) would have been appropriate. Wright's prescient views on causal complexities (sources, direction of flow of biochemical molecules, their interactions, and their phenotypic effects) of G-P relationships are found nowhere. Lewontin (1974) has further extended Waddington's epigenetic landscape metaphor into a more dynamic genotypeepigenetic-phenotype (GEP) space to represent all evolutionary changes across generations. Integrated GEP approaches are becoming integral aspects of predictive, preventive and regenerative medicine. The availability of new technologies and advances in computational methods suggest that the Wright-Waddington model holds tremendous promise toward addressing many fundamental questions in biology and human health. I applaud the editors for their efforts in bringing out this important book. To reiterate, this book is an invaluable contribution for understanding the intricacies of evolutionary processes as well as for devising interventional approaches to enhance healthy life span in humans. 
Competing interests

The author declares that he has no competing interests.

Received: 30 November 2014 Accepted: 15 December 2014

Published online: 01 February 2015

\section{References}

Fusco, G, Carrer, R, \& Serelli, E. (2014). The landscape metaphor in development. In A Minelli \& T Pradeu (Eds.), Towards a Theory of Development (pp. 114-128). Oxford: Oxford Univeristy Press.

Kacser, H, \& Burns, JA. (1981). The molecular basis of dominance. Genetics, 97, 639-666.

Lewontin, RC. (1974). The Genetic Basis of Evolutionary Change. New York: Columbia University Press.

Waddington, CH. (1942). The epigenotype. Endeavour, 1, 18-21.

Waddington, CH. (1975). The Evolution of an Evolutionist. Ithaca: Cornell University Press.

Wright, S. (1921). Correlation and causation. Journal of Agricultural Research, 20, 557-585.

Wright, S. (1934). Physiological and evolutionary theories of dominance. American Naturalist, 68, 25-53.

\section{Submit your manuscript to a SpringerOpen ${ }^{\circ}$} journal and benefit from:

- Convenient online submission

- Rigorous peer review

- Immediate publication on acceptance

Open access: articles freely available online

- High visibility within the field

- Retaining the copyright to your article 